\begin{abstract}
Two studies examined the effects of reliance on direct and media-based contact for information about Muslims on Americans' stereotypic beliefs of and negative emotions towards Muslims and support for public policies harming Muslims domestically and internationally. Results revealed that reliance on media for information about Muslims was positively associated with stereotypic beliefs, negative emotions, and support for harmful policies. Reliance on direct contact for information about Muslims produced the opposite results. Results from a 3-wave longitudinal design revealed that reliance on media and direct contact significantly predict changes in negative emotions which then predict changes in support for civil restrictions for Muslim Americans. We discuss the differential effects of reliance on media-based and direct contact in influencing intergroup outcomes.
\end{abstract}

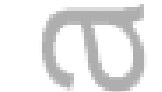

Keywords: contact, media effects, prejudice, intergroup, public policy

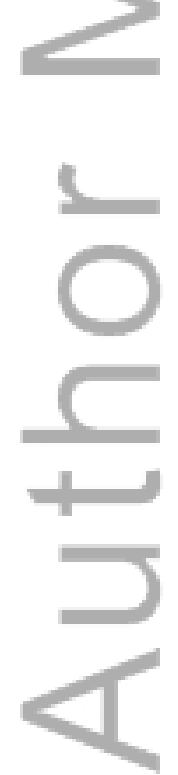

This is the author manuscript accepted for publication and has undergone full peer review but has not been through the copyediting, typesetting, pagination and proofreading process, which may lead to differences between this version and the Version of Record. Please cite this article as doi: $10.1111 /$ jcom.12234

This article is protected by copyright. All rights reserved. 


\section{Reliance on Direct and Mediated Contact and Public Policies Supporting Outgroup Harm}

Extant research suggests that our understanding of outgroups is influenced by various socializing agents including family, peers, and media. Although direct forms of intergroup contact in the United States have increased over the years due to changing racial demographics and policies, many individuals still rely on media as their primary source of information about outgroups (Mutz \& Goldman, 2010). For example, the majority of Americans report that media is their primary source of information about Muslims (Nisbet, Ostman, \& Shanahan 2009) and the influence of media on Americans' attitudes towards Muslims is stronger than that of other informational sources (Kalkan, Layman, \& Uslaner, 2009).

Past research suggests that the ways in which outgroups are represented in media ultimately influence people's perceptions, attitudes, and behaviors towards members of those groups (e.g., Harwood, Hewstone, Amichai-Hamburger, \& Tausch, 2012; Mastro, 2009). More specifically, media stereotypes of outgroups can influence negative attitudes and behaviors, including public policy decisions that harm members of the depicted outgroup (e.g., Mastro \& Kopacz, 2006; Ramasubramanian, 2011; Saleem, Prot, Anderson, \& Lemieux, 2015; Tan, Fujioka, \& Tan, 2000). Although many minority groups are negatively depicted in American media, negative stereotypes of Muslims are especially pervasive in media (Tukachinsky, Mastro, \& Yarchi, 2015). Muslims are frequently linked with violence, terrorism, and aggression across American media outlets, including cable news (Dixon \& Williams, 2015), newspapers (Nacos \& Torres-Reyna, 2007), and television and movies (Alsultany, 2012; Shaheen, 2009). These negative media portrayals influence negative beliefs towards Arabs, Muslims, and people of 
Middle Eastern descent (Das, Bushman, Bezemer, Kerkhof, \& Vermeulen, 2009; Nisbet, Ostman, \& Shanahan, 2009; Saleem \& Anderson, 2013). Importantly, although these identities are distinct, Americans often confound them as one identity and their attitudes towards these different groups are remarkably similar (Kteily, Bruneau, Waytz, \& Cotterill, 2015).

We examine the extent to which reliance on direct and media-based contact for information about Muslims influences Americans' stereotypes, emotions, and support for public policies that harm Muslims using cross-sectional correlational and longitudinal designs. The present study extends previous research in at least six ways. First, it is one of the few studies to simultaneously test the effects of reliance on direct and media-based contact on outgroup attitudes and public policies. Second, it examines the mediating roles of perceptions and emotions in understanding the link between reliance on different sources for information about outgroups and support for public policies harming members of those groups. Third, it goes beyond assessing preferential treatment of ingroup over outgroup members (i.e., ingroup positivity) and examines support for public policies that represent outgroup harm (discussed in detail in subsequent sections). Fourth, few empirical studies to date have examined the extent to which media stereotypes of Muslims influence Americans attitudes towards Muslims, despite the prevalence of these stereotypes in American media. The present study addresses this important gap. Fifth, the majority of past research on media stereotypes and public policy is done using correlational designs, which limits the causal interpretation of the results. We used a three-wave longitudinal design in Study 1 to provide stronger evidence for the direction and causality of the hypothesized relationships. Finally, Study 2 used a cross-sectional correlational design to 
generalize the findings of Study 1 using a more representative adult sample. We borrow from Intergroup Contact Theory (Allport, 1954) and Social Cognitive Theory (Bandura, 1986) to understand how reliance on direct and media-based contact influences intergroup outcomes.

\section{Intergroup Contact Theory}

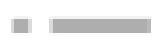

Intergroup contact theory suggests that contact between members of different groups can reduce prejudice and improve intergroup relations (Allport, 1952). Allport theorized that contact under certain conditions would be optimal: equal status between groups, institutional support of contact, shared goals between the groups involved, and cooperation between groups to meet those goals. Though contact effects under these conditions is the most powerful, contact in nonoptimal conditions can also influence positive intergroup outcomes (Pettigrew \& Tropp, 2006). The majority of work on intergroup contact has focused on direct (i.e., face-to-face) interactions with outgroup members however; recent work reveals that vicarious contact, including media-based contact, can also influence attitudes towards outgroups (Harwood et al., 2012).

Media-based contact. The importance of observing and learning from others is well established within the Social Cognitive Theory framework (Bandura, 1986; 2001). Specifically, real or virtual observations inform our schemas and associated cognitions about the social world, especially when they involve individuals with whom we identify (Bandura, 2001). These observations allow individuals to acquire new information or modify existing schemas involving outgroups ultimately increasing the likelihood of modeling the observed behavior in the short 
and long term (Bandura, 1986, 2001). Indeed, research suggests that observing positive intergroup contact, including media-based depictions, can influence positive attitudes towards outgroups (Joyce \& Harwood, 2012; Ortiz \& Harwood, 2007; Schiappa, Gregg, \& Hewes, 2005). Importantly, research suggests that positive exemplars of outgroup members, even in the absence of ingroup members, can influence positive intergroup outcomes. For example, media-based exposure to exemplary outgroup members can increase: a) perceptions that the outgroup has been the victim of discrimination (Bodenhausen, Schwarz, Bless, \& Wanke, 1995); b) external attributions of negative outgroup behavior (Power, Murphy, \& Coover, 1996); and c) support for public policies that benefit outgroup members (Ramasubramanian, 2011).

Although encouraging, the fact that minorities are mostly under or negatively represented in American media (Tukachinsky, Mastro, \& Yarchi, 2015; Behm-Morawitz \& Ortiz, 2013) dampens the enthusiasm for these positive effects. Indeed, numerous studies reveal that negative media stereotypes of outgroups influence negative attitudes and behavioral tendencies towards those groups (Mastro, 2009). These findings highlight a major barrier in expecting media-based contact to have positive effects on attitudes - if media portrayals of social groups are largely negative, then reliance on media as a source of information about these groups will result in negative attitudes and action tendencies towards that outgroup (Harwood et al., 2012).

Direct contact. Research examining face to face contact reveals that direct contact with outgroup members can reduce negative beliefs, affect, and behaviors towards outgroup members (Pettigrew \& Tropp, 2006). Furthermore, high-quality contact (e.g., cross-group friendships) is especially powerful in improving intergroup relations (Pettigrew \& Tropp, 2006). However, 
negative direct contact, similar to negative media-based contact, with outgroup members can result in deleterious outcomes. In fact, negative contact can increase group salience resulting in stronger effects on prejudice compared to positive contact (Barlow et al., 2012; Paolini, Harwood, Rubin, 2010). This is consistent with research revealing that people weigh negative information more heavily than positive (Baumeister, Bratslavsky, Finkenauer, \& Vohs, 2001). Differential effects of media-based and direct contact. The majority of studies have examined the effects of different types of contact in isolation (c.f., Mastro \& Tropp, 2004; Oritz \& Harwood, 2007; Paolini et al., 2014; Schiappa, Gregg, \& Hewes, 2006). This is problematic as individuals are likely exposed to and rely on both forms of contact involving outgroups (Mutz \& Goldman, 2010). Thus, it is imperative to study the effects of different types of contact on intergroup outcomes as well as their underlying mediating mechanisms (Harwood et al., 2012). Indeed, media stereotypes are especially influential when direct contact with outgroup members is limited (e.g., Armstrong, Neuendorf, \& Brentar, 1992; Fujioka, 1999). Direct, especially positive, contact with outgroup members provides individuals with new or alternative information about an outgroup which can counteract any negative cognitions activated by media stereotypes (Joyce \& Harwood, 2012). Void of these positive experiences, media stereotypes are likely to create and strengthen stereotypic cognitions of outgroups, which over time become automatized and applied when interacting with outgroup members (Bandura, 2001).

Reliance on media-based and direct contact for information about outgroups: Although exposure to and reliance on information are conceptually distinct they share some theoretical similarities in the context of intergroup dynamics. Media dependency theory suggests that people 
are especially likely to rely on media for information when their personal experience with or knowledge of the issue is limited (DeFleur \& Ball-Rokeach, 1989). This is consistent with Contact Theory which suggests that media-based contact effects are especially influential when direct contact is limited (Harwood et al., 2012). Although Contact Theory does not explicitly conceptualize exposure to different forms of contact as suggesting relative differences in the extent to which individuals rely on these contact sources for information, many media effects scholars interpret these effects as such (e.g., Behm-Morawitz \& Ortiz, 2012; Mastro, BehmMorawitz \& Ortiz, 2007; Ramasubramanian, 2013). For example, Ramasubramanian (2013) discovered that Whites who relied on media as opposed to direct contact as the primary source of information about African Americans were more likely to express stereotypic beliefs and prejudice against African Americans. In this study, participants had to report their primary sources of information about African Americans as either direct contact or media. Rather than examining the relative difference of reliance on personal versus media-based contact, a more interesting question is the extent to which reliance on direct and media-based contact differentially influences attitudes and behaviors towards an outgroup. We examine this question in the current study with respect to support for public policies harming Muslims.

\section{Media and Support for Public Policies Harming Outgroups}

Media's influence on public policies is significant as the majority of Americans obtain their public affairs information primarily from the media (Delli-Carpini \& Keeter 1996), and media can have a disproportionate influence on public opinion (Ball-Rokeach \& DeFleur, 1976). 
Indeed, correlational evidence suggests that Whites' recollection of negative media portrayals of African-Americans is significantly associated with negative stereotypes of African-Americans and in turn reduced support for affirmative action policies (Mastro \& Kopacz, 2006; Tan, Fujioka, \& Tan, 2000). Ramasubramanian (2011) used an experimental design to show that White participants primed with stereotypic images of African American celebrities, relative to participants primed with counterstereotypic images, displayed more stereotypic beliefs and prejudicial feelings, and were less likely to support affirmative action policies.

Note that all of these studies examine support for one specific public policy (i.e., affirmative action). Research reveals that support for affirmative action is motivated by ingroup positivity rather than outgroup harm (Lowery et al., 2006) which is theoretically and conceptually distinct from intentions to harm an outgroup (Brewer, 2001; 2010). Ingroup preference may reflect positive sentiments (trust, empathy, cooperation) towards the ingroup that are withheld from an outgroup. Outgroup harm, however, entails active hostility, derogation, and intent to harm an outgroup without any necessary benefit to the ingroup (Brewer, 2001; 2010). Most forms of intergroup bias occur with the primary motivation to benefit the ingroup rather than harm the outgroup (Mummendey \& Otten, 2001).

However, these constraints disappear when outgroups are perceived as threatening and aggressive (Stephan \& Stephan, 2000), or when outgroups are viewed with hatred or contempt emotions that justify outgroup harm above and beyond ingroup benefit (Mackie, Devos, \& Smith, 2000). Threatening outgroups arouse aggressive cognitions, negative emotions and behaviors representative of outgroup harm (Riek, Mania, \& Gaertner, 2000). Scholars further 
suggest that negative emotions toward an outgroup are key in differentiating motivations of ingroup love from outgroup harm (Brewer, 2010; Mackie, et al., 2000; Mummendey \& Otten, 2001). This is important as past studies on media stereotypes have mostly focused on outgroup cognitions rather than emotions (c.f., Seate \& Mastro, 2015). We address this limitation in the present work by examining the mediating role of emotions and perceptions in understanding the effects of reliance on direct and media-based contact on support for policies harming Muslims.

\section{Overview of the Current Studies}

The above review of existing theory and empirical evidence suggests that Americans' reliance on media for information about Muslims will positively influence negative perceptions of, and emotions towards, Muslims, and subsequently support for public policies harming Muslims. However, Americans' reliance on direct contact, especially their Muslim friends, for information about Muslims will inversely influence these outcomes. We tested these predictions across two studies using two different samples and designs.

\section{Study 1}

Study 1 used a three-wave longitudinal design to test the effects of reliance on direct and mediabased contact for information about Muslims on changes in perception of, and emotions towards, Muslims, and support for policies harming Muslims. Based on Intergroup Contact Theory and Media Dependency Theory, we expected reliance on direct contact for information about Muslims at Time 1 to be negatively associated with perceptions of Muslims as aggressive and with negative emotions towards Muslims at Time 2. Although contact in general is known 
reduce prejudice our assessment of contact specifically included friendships with Muslims which is especially likely to influence positive intergroup outcomes (Turner, Hewstone, \& Voci, 2007). However, given that Muslims are represented negatively in American media (see citations above); we expected reliance on media for information about Muslims at Time 1 to be positively associated with perceptions of Muslims as aggressive and with negative emotions towards Muslims at Time 2. Finally, consistent with previous work, we expected an interaction between reliance on media and direct contact, such that the effects of reliance on media on perceptions of, and emotions towards, Muslims are significant for those low, relative to high, on reliance on direct contact for information about Muslims.

Hypotheses 1a and 1b: Reliance on direct contact as a source of information about Muslims at Time 1 will be inversely associated with perceptions of Muslims as aggressive at Time 2 (H1a) and with negative emotions towards Muslims at Time 2 (H1b).

Hypotheses 2a and 2b: Reliance on media as a source of information about Muslims at Time 1 will be positively associated with perceptions of Muslims as aggressive at Time 2 (H2a) and with negative emotions towards Muslims at Time 2 (H2b).

Hypotheses 3a and 3b: Reliance on media as a source of information about Muslims at Time 1 will be positively associated with perceptions of Muslims as aggressive at Time 2 and with negative emotions towards Muslims at Time 2 for those low, relative to high, on reliance on contact for information about Muslims (H3a and $\mathrm{H} 3 \mathrm{~b})$.

Based on past research predicting outgroup harm, we expected perceptions of Muslims as aggressive and negative emotions towards Muslims to positively predict support for public 
policies that harm Muslims internationally and domestically. Though there is some evidence that thinking of outgroups within a superordinate identity (e.g., American) reduces outgroup prejudice (Gaertner \& Dovidio, 2000), research suggests that Americans' attitudes towards Muslim Americans is not significantly different than their attitudes towards Muslims living abroad (Kteily et al., 2015; Saleem et al., 2015; Sides \& Gross, 2013). Thus, we expected our hypothesized mediators (perceptions and emotions) to influence Americans' support for public policies involving both, Muslims living abroad and Muslim Americans.

Hypotheses 4a and 4b: Perceptions that Muslims are aggressive at Time 2 will be positively associated with support for civil restrictions for Muslim Americans at Time 3 (H4a) and with support for military action in Muslim countries at Time 3 (H4b).

Hypotheses 5a and 5b: Negative emotions toward Muslims at Time 2 will be positively associated with support for civil restrictions for Muslim Americans at Time 3 (H5a) and with support for military action in Muslim countries at Time 3 (H5b).

Hypothesis 6: The relationship between sources of information about Muslims and support for public policies harming Muslims will be mediated by perceptions of Muslims as aggressive and by negative emotions towards Muslims.

Importantly, we controlled for theoretically relevant individual differences (American identification, right wing authoritarianism) known to be associated with negative outgroup attitudes and outgroup harm (Brewer, 2010; Sides \& Gross, 2013). Additionally, we controlled for social desirability as responses on explicit measures can be affected by such concerns (Hewstone, Rubin, \& Willis, 2002). 


\section{Study 1 Methods}

\section{Participants}

Participants were 222 undergraduate students (159 female, 58 male, 5 unidentified; Mage = 18.76 years) enrolled in introductory communication courses at a large university in the $=$

Midwestern United States, and received course credit for their participation. Most students selfidentified as White (82.9\%), followed by Asian (9.5\%), African American (3.6\%), Hispanic (1.4\%), and other (1.8\%). Three students self-identified as Muslim and four students were suspicious of the study's hypotheses as assessed by open-ended questions at the end of the study. These students were excluded from final data analysis. Data were collected across two semesters ${ }^{1}$ in three waves using online surveys at a 3 -week interval, over a 9 -week period. We will refer to these three survey assessments as T1, T2, and T3, respectively. There was a moderate level (15-16\%) of attrition on major outcome variables from T1 to T3 across 9 weeks ${ }^{2}$. Attrition was calculated as the number of participants at T3 compared to T1. The final response rate for the original sample was $83.81 \%$. Missing data were appropriately handled with multiple imputation methods.

\section{Measures}

Table 1 displays the descriptive statistics, alphas, and correlations of key variables.

\footnotetext{
${ }^{1}$ There were no significant differences across the two semesters on key outcomes, thus these data were combined. ${ }^{2}$ There was no significant difference between those who dropped out and those who remained in the study in terms of age $(t(208)=.915, p=.361)$, gender $(t(208)=.463, p=.644)$, and race $(t s(208)=1.205, p=.230)$.
} 
Reliance on media-based contact (T1). Participants rated the extent to which four media sources (newspapers, TV, movies, Internet) influenced their opinions about Muslims on a 1 (not at all) to 7 (a lot) scale (Saleem \& Anderson, 2013). These items were averaged together.

Reliance on direct contact (T1). Participants were asked a) the extent to which they relied on direct personal contact for information about Muslims on a scale ranging from 1 (not at all) to $7($ a lot $)(M=3.87 ; S D=2.28)($ Saleem \& Anderson, 2013), b) the number of Muslims they know (Turner, Hewstone, \& Voci, 2007) on a scale ranging from 0 (none) to 11 (many) (M $=4.56 ; S D=3.53)$, and $\mathrm{c})$ of the Muslims they know, how many would they consider friends $(M$ $=3.38 ; S D=3.26$ ) using the same response scale ${ }^{3}$. A single measure of reliance on personal contact was created by standardizing and averaging the three scores.

Negative emotions towards Muslims (T2). Participants indicated the extent to which they feel eight emotions towards Muslims (anger, disgust, fury, fear, irritation, frustration, threat, hostility) on a scale ranging from 1 (not at all) to 5 (extremely) (Mackie, Devos, \& Smith, 2000).

Perceptions of Muslims as aggressive (T2). Participants rated their agreement with four statements (e.g., "Muslims are violent," "Most of the terrorists in the world are Muslim") on a scale ranging from 1 (strongly disagree) to 5 (strongly agree) (Pratto et al., 1994).

Support for civil restrictions for Muslim Americans (T3). Participants responded to six statements (e.g., It is okay for the government to secretly monitor Muslim Americans without their consent or awareness, Muslims Americans should not be allowed to vote) on a scale ranging from 1 (strongly disagree) to 5 (strongly agree) (Saleem et al., 2015).

\footnotetext{
${ }^{3}$ Study 2 means and standard deviation for a) reliance on direct contact, $M=3.44, S D=2.35$; b) number of Muslims you know, $M=3.16, S D=3.05$; c) the number of Muslims you are friends with, $M=2.67, S D=2.75$.
} 
Support for military action in Muslim countries (T3). Participants indicated their agreement with seven statements (e.g., The use of drone attacks in Muslim countries is necessary, It is absolutely necessary to remove or reduce the influence of Islam from the Middle East) on a scale ranging from 1 (strongly disagree) to 5 (strongly agree) (Henry et al., 2005).

Control variables. Control variables were only assessed in Wave 1 as trait measures are $=$ unlikely to change in a context of 9 weeks.

Identification as an American. (Doosje, Ellemers, \& Spears, 1995). Participants responded to four statements (e.g., I feel proud to be an American) on a scale ranging from 1 (strongly disagree) to 7 (strongly agree) $(M=5.82 ; S D=1.13 ;$ alpha $=.89)$.

Right wing authoritarianism. Participants responded to 15-statements (e.g., The "oldfashioned ways" and "old-fashioned values" still show the best way to live) using a 1 (Strongly Disagree) to 5 (Strong Agree) scale $(M=2.43 ; S D=.48 ;$ alpha $=.76)($ Zakrisson, 2005).

Social desirability scale. Participants indicated whether each of the 11 statements (I'm always willing to admit it when I make a mistake) were true/false in describing them (Reynolds, 1982). Items indicating social desirability were summed, $M=4.51 ; S D=2.42 ;$ alpha $=.65$.

Political orientation. Participants indicated their political orientation on a scale ranging from 1 (strongly conservative) to 7 (strongly liberal), $M=4.33 ; S D=1.69$.

Time 1 Measures. Time 1 baseline measures of hypothesized mediating variables (negative emotions towards Muslims and perceptions of Muslims as aggressive) and outcome variables (support for civil restrictions for Muslim Americans and support for military action in Muslim countries) were controlled in final analyses to examine changes in these outcomes. 


\section{Study 1 Results and Discussion}

Table 1 summarizes the bivariate correlations of key variables used in the model. Main analysis consisted of testing a path model using Stata 13.1 (StataCorp, College Station, TX, USA) within the full-information maximum-likelihood (FIML) framework. Using this approach, we tested all of our hypotheses and the indirect effects of predictor variables passing through two proposed mediators simultaneously in one model. Overall model fit was determined by using the fit statistics recommended by $\mathrm{Hu}$ and Bentler (1999). The fit indices indicated an excellent fit, $C^{2}(22)=36 . .3253, p=.029, \mathrm{CFI}=0.973, \mathrm{RMSEA}=.055(90 \%$ interval from .018 to .086$)$.

\section{Testing Main Hypotheses}

Figure 1 presents the results of the theoretical SEM model designed to test H1a-H5b.

Hypotheses 1a and 1b. Reliance on direct contact (T1) inversely predicted changes in negative emotions towards Muslims $(\mathrm{T} 2)\left({ }^{2}=-.22, p<.01\right)$, but not changes in perceptions that Muslims are aggressive $(\mathrm{T} 2)\left(^{2}=.00, p=.98\right)$, providing support for H1b but not H1a.

Hypotheses $\mathbf{2 a}$ and $\mathbf{2 b}$. Reliance on media-based contact (T1) positively predicted changes in negative emotions towards Muslims (T2) $\left({ }^{2}=.35, p<.001\right)$, but not changes in perceptions that Muslims are aggressive $\left({ }^{2}=.08, p=.24\right)$, supporting $\mathrm{H} 2 \mathrm{~b}$ but not $\mathrm{H} 2 \mathrm{a}$.

Hypothesis $3 \mathbf{a}$ and $\mathbf{3 b}$. Contrary to hypotheses $3 \mathrm{a}$ and $3 \mathrm{~b}$, the interaction between reliance on media and direct contact did not significantly predict changes in perceptions that 
Muslims are aggressive $\left({ }^{2}=.01, p=.89\right)$ and changes in negative emotions towards Muslims (T2) $\left({ }^{2}=.00, p=.98\right)$.

Hypotheses $4 \mathbf{a}$ and 4 b. Perceptions that Muslims are aggressive (T2) positively predicted changes in support for civil restrictions for Muslim Americans (T3) $\left({ }^{2}=.20, p<.01\right)$, but not changes in support for military action in Muslim countries $(\mathrm{T} 3)\left({ }^{2}=.06, p=.36\right)$, confirming $\mathrm{H} 4 \mathrm{a}$ but not $\mathrm{H} 4 \mathrm{~b}$.

Hypotheses 5a and 5b. Negative emotions towards Muslims (T2) positively predicted changes in support for civil restrictions for Muslim Americans $(\mathrm{T} 3)\left({ }^{2}=.23, p<.01\right)$ but not changes in support for military action in Muslim countries $(\mathrm{T} 3)\left({ }^{2}=.07, p=.29\right)$, confirming H5a but not H5b. Overall, 56.04\% of the variance in support for civil restrictions for Muslim Americans and 58.09\% of the variance in support for military action in Muslim countries was explained by the predictors included in these models.

\section{Testing Mediating Effects}

In line with H6, we tested the mediating role of negative emotions towards Muslims and perceptions that Muslims are aggressive between our predictor variables (reliance on direct and media-based contact) and outcome variables (support for civil restrictions and military action). We first isolated the indirect effect of each mediator in the estimation procedure. Specifically, we performed both the delta and bootstrapping methods to obtain the parameter estimates and standard errors for the indirect effect of each mediator. The findings yielded a similar pattern of the results, and thus we report results based on the delta method here. 
Reliance on media-based contact (T1) yielded a significant indirect effect on changes in support for civil restrictions for Muslim Americans (T3) through negative emotions (T2) (standardized indirect effect $=.04, \mathrm{SE}=.0319 p=.025)$. Similarly, reliance on direct contact (T1) had a moderately significant indirect effect on changes in support for civil restrictions for Muslim Americans (T3) through negative emotions (T2) (standardized indirect effect $=-.03, \mathrm{SE}$ $=.017, p=.088)$. Mediation tests for support for military action were not performed as the direct link between our hypothesized mediators (T2) and changes in support for military action in Muslim countries (T3) was nonsignificant in earlier analyses (H4b and H5b).

Overall, results revealed that reliance on media for information about Muslims was positively associated with changes in negative emotions towards Muslims but not significantly associated with changes in perceptions of Muslims as aggressive. Reliance on direct contact for information about Muslims was inversely associated with changes in negative emotions towards Muslims but not significantly associated with changes in perceptions of Muslims as aggressive. In other words, reliance on vicarious and direct contact for information about Muslims might have a stronger influence in changing emotions towards, rather than perceptions of, Muslims. Although perceptions of Muslims as aggressive were positively associated with support for harming Muslims domestically and internationally, the latter effect was nonsignificant. Similarly, negative emotions towards Muslims were positively associated with changes in support for harming Muslims domestically and internationally, however the latter effect was nonsignificant. These results suggest that our hypothesized mediators may predict changes in support for public policies relevant to Muslim Americans better than public policies relevant to 
Muslims abroad. The relationship between our predictor variables (reliance on direct and mediabased contact) and changes in support for civil restrictions was mediated by negative emotions, but not by perceptions of Muslims as aggressive. Finally, these results were obtained while controlling for important theoretically relevant variables as well as Time 1 baseline measures.

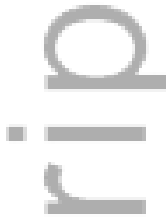

\section{Study 2}

Study 2 was designed to replicate the findings of Study 1 using a different sample. Specifically, we used a cross-sectional correlational design to test the hypotheses of Study 1 using a more representative sample of American adults.

\section{Study 2 Method}

\section{Participants}

Data collection occurred through the use of Research Now, a Web-based survey research company, whose panels ensured a more representative sample than Study 1. Research Now recruits its panel participants through two methods: self-registration through a Web site and proactive recruitment by representatives of the company through third-party lists. Participants received cash-equivalent points that can be exchanged for airline miles, gift cards, magazine subscriptions, and other rewards. Quotas were set to achieve equal representation for party identification (Republicans or Democrats). The final data set included 351 participants (Mage = 50.8 years; $54.7 \%$ female). Most respondents were White (84.9\%), followed by Asian (6\%), Black (5.4\%), Hispanic (2\%), Native American (1.1\%), and Other (0.6\%). 


\section{Measures}

We used all the same measures from Study 1. Table 2 displays descriptive statistics, including alphas, for all measures used in Study 2.

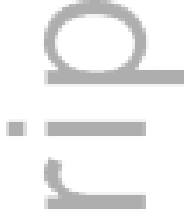

Study 2 Results and Discussion

\section{Testing Main Hypotheses}

Figure 2 presents the results of SEM analysis, using full-information maximum-likelihood (FIML) estimations. The model demonstrated excellent fit for the data, $\mathcal{C}^{2}(11)=32.60, p=.001$, $\mathrm{CFI}=.979, \mathrm{RMSEA}=.075(90 \%$ interval from .046 to .105$)$.

Hypotheses 1a and 1b. Reliance on direct contact was negatively related to perceptions that Muslims are aggressive $\left({ }^{2}=-.14, p=.001\right)$ but was not significantly related to negative emotions towards Muslims $\left({ }^{2}=.02, p=.610\right)$, supporting H1a but not H1b.

Hypotheses $2 \mathbf{a}$ and $2 \mathbf{b}$. Consistent with hypotheses $2 \mathrm{a}$ and $2 \mathrm{~b}$, reliance on media-based contact was positively related to perceptions that Muslims are aggressive $\left({ }^{2}=.24 p<.001\right)$ and negative emotions towards Muslims $\left({ }^{2}=.41, p<.001\right)$.

Hypothesis $3 \mathbf{a}$ and $3 \mathbf{b}$. $\mathrm{H} 3 \mathrm{a}$ and $\mathrm{H} 3 \mathrm{~b}$ predicted an interaction between reliance on direct and media-based contact and negative perceptions of and emotions towards Muslims. The interaction term yielded a significant effect on perceptions that Muslims are aggressive $\left(^{2}=.13\right.$, $p=.003)$ and negative emotions towards Muslims $\left({ }^{2}=.11, p=.013\right)$. We further probed these interactions using the simple effects test approach to understand the effect of reliance on contact 
at +1 and -1 standard deviation of reliance on media. With respect to perceptions that Muslims are aggressive, reliance on contact was significant at $-1,[t(347)=-3.76, p<.01]$ standard deviation but nonsignificant at $+1,[t(347)=1.09, p=.27]$ standard deviation of reliance on media for information about Muslims (Figure 3). Figure 3 suggests that participants who heavily relied on direct contact for information about Muslims displayed lower stereotypic beliefs only when they did not highly rely on media for information about Muslims. Indeed, the difference between those who highly relied on direct contact versus those who did not was nonsignificant at high levels of reliance on media for information about Muslims. With respect to negative emotions towards Muslims, reliance on contact was nonsignificant at $-1,[t(347)=-1.06, p<.01]$ standard deviation but marginally significant at $+1,[t(347)=2.00, p=.05]$ standard deviation of reliance on media for information about Muslims (Figure 4). Figure 4 suggests that the relationship between reliance on contact and negative emotions was only significant for those who highly relied on media but not for those who had lower levels of reliance on media. These results are contradictory to those obtained for the perceptions outcome however; caution should be taken when interpreting this interaction given the marginal effect.

Hypotheses $4 \mathbf{a}$ and $4 \mathbf{b}$. Confirming hypotheses $4 \mathrm{a}$ and $4 \mathrm{~b}$, perceptions that Muslims are aggressive was positively related to support for civil restrictions for Muslim Americans $\left(^{2}=.36\right.$, $p<.001)$ and support for military action in Muslim countries $\left({ }^{2}=.29, p<.001\right)$.

Hypotheses 5a and 5b. Consistent with hypotheses 5a and 5b, negative emotions towards Muslims was positively associated with support for civil restrictions for Muslim Americans $(2=.31, p<.001)$ and support for military action in Muslim countries $\left({ }^{2}=.18, p<\right.$ 
$.01)$. Overall, 57.62\% of the variance in support for civil restrictions for Muslim Americans and $47.04 \%$ of the variance in support for military action in Muslim countries was explained by the predictors included in these models.

\section{Testing Mediating Effects}

As in Study 1, we tested the significance of mediating effects using delta method. We expected that our predictor variables (reliance on direct and media-based contact) would influence support for harmful policies (civil restrictions and military actions) through two distinct routes: perceptions that Muslims are aggressive and negative emotions towards Muslims. Results revealed that media-based contact had a significant indirect effect on support for civil restrictions for Muslim Americans through negative emotions (standardized indirect effect $=.13$, $\mathrm{SE}=.024, p<.001)$ and through perceptions that Muslims are aggressive (standardized indirect effect $=.09, \mathrm{SE}=.020, p<.001)$. Furthermore, media-based contact had a significant indirect effect on support for military action in Muslim countries through perceptions that Muslims are aggressive (standardized indirect effect $=.07, \mathrm{SE}=.019, p<.001$ ) and through negative emotions (standardized indirect effect $=.07, \mathrm{SE}=.024, p<.01$ ). Mediation results also revealed a significant indirect effect of reliance on direct contact on support for civil restrictions for Muslim Americans through perceptions that Muslims are aggressive (standardized indirect effect $=-.05, \mathrm{SE}=.018, p<.01)$, but not significantly through negative emotions (standardized indirect effect $=.01, \mathrm{SE}=.014, p=.612)$. Perceptions that Muslims are aggressive significantly 
mediated the relation between direct contact and support for military action in Muslim countries (standardized indirect effect $=-.04, \mathrm{SE}=.015, p<.01)$.

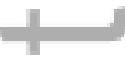

\section{Overall Discussion}

Two studies examined the extent to which reliance on direct and media-based contact for information about Muslims influenced Americans' stereotypic beliefs, negative emotions, and support for public policies harming Muslims domestically and internationally. Across both studies, reliance on media and direct contact were associated with perceptions of Muslims as aggressive and negative emotions towards Muslims in the expected direction. However, longitudinal results from Study 1 revealed that reliance on media and direct contact significantly predict changes in negative emotions but not changes in perceptions. The interaction between reliance on media and direct contact was nonsignificant in Study 1 but was significant in Study 2. Simple effects analyses revealed that the positive effects of contact in reducing bias towards Muslims may be suppressed for participants who also heavily rely on media, likely due to the negative representation of Muslims in media. This interpretation warrants caution given the inconsistencies and differences in samples and design across the two studies.

Results revealed that perceptions of Muslims as aggressive and negative emotions towards Muslims were positively related to support for public policies harming Muslims internationally and domestically. However, longitudinal results revealed that changes in support for civil restrictions were predicted by negative emotions but not perceptions. Similarly, changes in support for military action were not significantly predicted by perceptions or emotions, 
although both hypothesized mediators were positively associated with support for military action in Muslim countries. Study 1 mediation results revealed that the effect of reliance on media and direct contact on changes in support for civil restrictions for Muslim Americans was mediated by negative emotions but not perceptions. These results are consistent with previous studies highlighting the importance of emotions relative to beliefs in predicting outgroup harm (Saleem $=$ et al., 2015; Talaska, Fiske, \& Chaiken, 2008) and policies involving outgroups (Brader, Valentino, \& Suhay, 2008). Another important finding is that reliance on media and direct contact influenced changes in negative emotions towards, but not perceptions of, Muslims as aggressive. It is possible that information obtained through media and direct contact about Muslims is more effective in changing emotions towards, rather than perceptions of, Muslims. Indeed, work on contact theory suggests that contact effects are greater for affective compared to cognitive outcomes (Pettigrew \& Tropp, 2006).

This work has several theoretical and methodological strengths. Theoretically speaking, this is one of the few studies to date examining the simultaneous effects of reliance on direct and media-based sources for information on support for public policies targeting an outgroup. This is important as individuals often learn about outgroups from multiple sources (Mutz \& Goldman, 2010). By simultaneously assessing the extent to which individuals rely on direct and mediabased contact for information about Muslims we were able to examine the unique and interactive effects of these predictors on the outcomes of interest. Furthermore, we identified mediating mechanisms that explain how reliance on media and direct contact can effect support for public policies targeting outgroups. Overall, this research highlights the difficulty in improving attitudes 
and public policies towards marginalized groups. Even though the changing demographics of the United States allows individuals opportunities to interact with members of outgroups and establish positive relations, mainstream media's tendency to negatively depict outgroups perpetuates negative attitudes towards and support for harmful policies targeting these groups. It is important to note that we assess support for public policies (military action, civil restrictions) that are explicitly intended to harm Muslims rather than policies that passively harm an outgroup (e.g., affirmative action) or are race-neutral ${ }^{4}$. Support for the latter policies is implicitly associated with certain groups (e.g., African Americans), however, the policies do not explicitly and exclusively target members of one outgroup. The policies that we examine in the present study are explicitly and exclusively harming Muslims. This is an important distinction because support for intentionally harmful policies is a clear representative of active harm, which is often predicted by negative emotions and threatening perceptions (Brewer, 2001, 2010).

Methodologically, the present work addresses the limitations of past studies in several ways. The majority of previous media psychology research exploring the effects of media stereotypes and public policies has been correlational in design, which limits its causal interpretations (e.g., Tan et al., 2000; Mastro \& Kopacz, 2006). Study 1 of the present research used a three-wave longitudinal design to provide stronger evidence for a) the direction of the hypothesized relationships, b) predicting dynamic change from one time point to another, and c) testing the underlying mediating mechanisms involved in understanding the effects of direct and media-based contact on support for public policies harming outgroups. Additionally, Study 2

${ }^{4}$ Policies such as crime and welfare are inherently race-neutral as they affect all society members but support for them is heavily influenced by racial attitudes due to their implicit association with certain groups (Gilens, 1996). 
provided evidence for the generalizability of Study 1 results by using a more representative adult sample. Moreover, by controlling for theoretically relevant individual differences variables (American identification, right-wing authoritarianism, social desirability, political orientation) known to be associated with outgroup harm, we examined the unique effects of reliance on direct and media-based contact for information about Muslims.

Finally, the present study is one of the few studies in the media psychology literature to examine attitudes and support for public policies targeting Muslims. This is alarming when considering the following: (a) the overwhelmingly negative representation of Muslims in the American media (e.g., Dixon \& Williams, 2015; Nacos \& Torres-Reyna, 2007); (b) the fact that most Americans rely on media as their primary source of information about Muslims (Nisbet et al., 2009); (c) media's role in influencing negative attitudes towards Muslims is more important than other sources (Kalkan, Layman, \& Uslaner, 2009); (d) most Americans do not have direct contact with Muslims in their daily lives (e.g., Jung, 2012), and (e) media stereotypes are especially detrimental for infrequently encountered groups (e.g., Armstrong, Neuendorf, \& Brentar, 1992). Thus, because most Americans lack direct contact with Muslims, they rely on media sources that represent Muslims in a negative light, ultimately increasing negative attitudes and support for harmful public policies targeting Muslims. Results from the present study suggest that media may have a significant role in shaping Americans' recent increase in support for civil restrictions for Muslim Americans (e.g., The Brookings Institute, 2011).

Important limitations of this research warrant attention. First, as discussed earlier, despite their theoretical similarities in the context of intergroup dynamics, exposure to and reliance on 
information are conceptually distinct. Indeed, Intergroup Contact Theory outlines the hypothesized effects of quantity and quality of contact but not necessarily reliance on those contacts for information (Allport, 1954). By assessing the extent to which individuals rely on direct contact and media sources for information about Muslims we may have indirectly assessed participants' own biases regarding the influence of these sources on their own attitudes. Future $=$ research should more clearly differentiate the effects of exposure to and reliance on difference sources in understanding their unique and combined effects on intergroup outcomes.

Second, the predictor variables used in this research do not isolate the effects of reliance from valence. Specifically, the reliance on direct contact measure included one positive valence (friendships with Muslims), and two nonvalence items. However, the reliance on media-based contact measure was nonvalenced. It did not explicitly assess whether participants were exposed to negative images of Muslims in the media. It is possible that some individuals who rely on media for information about Muslims are exposed to positive representations of Muslims, though this seems unlikely based on research documenting the negative representation of Muslims across American media outlets (see citations above). Nevertheless, future research should more clearly isolate the effects of reliance and valence when examining the effects of contact on intergroup outcomes, especially because exposure to positive representation of Muslims in news can decrease support for harmful policies targeting Muslims (Saleem et al., 2015).

Overall, these studies address several gaps in the literature. Specifically, that direct and media-based contact can have long-term effects on attitudes towards and support for harmful public policies explicitly and exclusively targeting minority groups. Whereas direct contact 
reduces negative attitudes and outgroups harm, media-based contact produces the opposite effect. Exposure to negative representation of Muslims in the media not only influences negative attitudes towards Muslims but extends to support for public policies harming Muslims. These findings make a strong case for the need for more diverse and positive representations of Muslims in mainstream American media. Simultaneously, there is a need for continued opportunities in the workplace, in educational settings, in neighborhoods, and elsewhere in the community for non-Muslims to interact in meaningful ways with Muslims.
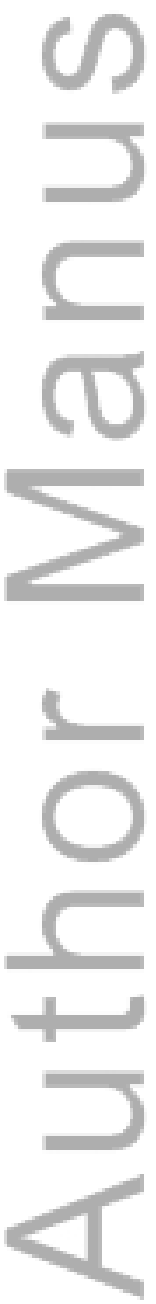


\section{References}

Allport, G. W. (1954). The nature of prejudice. Reading, MA: Addison-Wesley.

Alsultany, E. (2012). Arabs and Muslims in the media: Race and representation after 9/11. New "York. New York University Press.

Armstrong, G. B., Neuendorf, K. A., \& Brentar, J. E. (1992). TV entertainment, news, and racial perceptions of college students. Journal of Communication, 42(3), 153-179.

Ball-Rokeach, S. J, \& Defleur, M. L. (1976). A dependency model of mass media effects.

Communication Research, 12, 485-510.

Bandura, A. (1986). Self-efficacy. In A. Bandura (Ed.), Social foundations of thought and action (pp. 390-453). Englewood Cliffs, N.J.: Prentice Hall.

Bandura, A.(2001). Social cognitive theory: An agentic perspective. Annual review of psychology, 52(1), 1-26.

Barlow, F. K., Paolini, S., Pedersen, A., Hornsey, M. J., Radke, H. R., Harwood, J., Rubin, M., \& Sibley, C. G. (2012). The contact caveat: negative contact predicts increased prejudice more than positive contact predicts reduced prejudice. Personality and Social Psychology Bulletin, 38(12), 1629-1643.

Baumeister, R. F., Bratslavsky, E., Finkenauer, C., \& Vohs, K. D. (2001). Bad is stronger than good. Review of General Psychology, 5, 323-370.

Behm-Morawitz, E., \& Ortiz, M. (2012). Race, ethnicity, and the media. In K. Dill (Ed.), The Oxford handbook of media psychology (pp. 252-264). New York, NY: Oxford University Press. 
Bodenhausen, G., Schwarz, N., Bless, H, \& Wänke, M. (1995). Effects of atypical exemplars on racial beliefs: Enlightened racism or generalized appraisals? Journal of Experimental Social Psychology, 31, 48-63.

Brader, T., Valentino, N. A., \& Suhay, E. (2008). What triggers public opposition to immigration? Anxiety, group cues, and immigration threat. American Journal of Political Science, 52(4), 959-978.

Brewer, M. B. (2001). Ingroup identification and intergroup conflict. In R. D. Ashmore, L. Jussim, \& D. Wilder (Eds.), Social identity, intergroup conflict, and conflict reduction, Vol. 3, pp. 17-41. New York: Oxford University Press.

Brewer, M. B. (2010). Intergroup Relations. In R.F. Baumeister \& E.J. Finkel's (Eds), Advanced social psychology: The state of the science (pp. 531-567). Oxford University Press.

Das, E., Bushman, B. J., Bezemer, M. D., Kerkhof, P., \& Vermeulen, I. E. (2009). How terrorism news reports increase prejudice against outgroups: A terror management account. Journal of Experimental Social Psychology, 45(3), 453-459.

Delli Carpini, M. X., \& Keeter, S. (1996). What Americans know about politics and why it matters. New Haven, CT: Yale University Press.

Dixon, T. L., \& Williams, C. L. (2015). The changing misrepresentation of race and crime on network and cable news. Journal of Communication, 65(1), 24-39.

Doosje, B., Ellemers, N., \& Spears, R. (1995). Perceived intragroup variability, group status and identification. Journal of Experimental Social Psychology, 31(5), 410-436. 
Duckitt, J. (2006). Differential effects of right wing authoritarianism and social dominance orientation on outgroup attitudes and their mediation by threat from and competitiveness to outgroups. Personality and Social Psychology Bulletin, 32(5), 684-696.

Fujioka, Y. (1999). Television portrayals and African American stereotypes: Examination of contact effects when direct contact is lacking. Journalism \& Mass Communication

$=$ Quarterly, 76, 52-75.

Gaertner, S. L., \& Dovidio, J. F. (2000). Reducing intergroup bias: The common ingroup identity model. Philadelphia: Psychology Press.

Gilens, M. (1996) "Race coding" and white opposition to welfare. American Political Science Review, 90, (3), 593-604.

Greenwald, A. G., \& Pettigrew, T. F. (2014). With malice toward none and charity for some: Ingroup favoritism enables discrimination. American Psychologist, 69 (7), 669-684.

Harwood, J., Hewstone, M., Amichai-Hamburger, Y., \& Tausch, N. (2012). Intergroup contact: An integration of social psychological and communication perspectives. Communication Yearbook 36, 55-102.

Henry, P. J., Sidanius, J., Levin, S., \& Pratto, F. (2005). Social dominance orientation, authoritarianism, and support for intergroup violence between the Middle East and America. Political Psychology, 26, 569-583.

Hewstone, M., Rubin, M., \& Willis, H. (2002). Intergroup bias. Annual Review of Psychology, 53(1), 575-604. 
Hu, L. T., \& Bentler, P. M. (1999). Cutoff criteria for fit indexes in covariance structure analysis: Conventional criteria versus new alternatives. Structural Equation Modeling: A multidisciplinary Journal, 6(1), 1-55.

Joyce, N., \& Harwood, J. (2012). Improving intergroup attitudes through televised vicarious intergroup contact: Social cognitive processing of ingroup and outgroup $=$ information. Communication Research, 0093650212447944.

Jung, J.H.'(2012). Islamophobia? Religion, contact with Muslims, and the respect for Islam. Review of Religious Research, 54(1), 113-126.

Kalkan, K. O., Layman, G. C., \& Uslaner, E. M. (2009). Bands of others? Attitudes toward Muslims in contemporary American society. Journal of Politics, 71(3), 847-862.

Kteily, N., Bruneau, E.,Waytz, A. Cotterill, S. (2015). 'The ascent of man': A theoretical and empirical case for blatant dehumanization. Journal of Personality and Social Psychology, 109(5), 901-931.

Lowery, B. S., Unzueta, M. M., Knowles, E. D., \& Goff, P. A. (2006). Concern for the in-group and opposition to affirmative action. Journal of personality and social psychology, 90(6), $961-974$.

Mackie, D. M., Devos, T., \& Smith, E. R. (2000). Intergroup emotions: Explaining offensive action tendencies in an intergroup context. Journal of personality and social psychology, 79(4), 602-616.

Mastro, D. (2009). Effects of racial and ethnic stereotyping. Media effects: Advances in theory and research, 3, 325-341. 
Mastro, D., Behm-Morawitz, E., \& Ortiz, M. (2007). The cultivation of social perceptions of Latinos: A mental models approach. Media Psychology, 9(2), 347-365.

Mastro, D. E., \& Kopacz, M. A. (2006). Media representations of race, prototypicality, and policy reasoning: An application of self-categorization theory. Journal of Broadcasting \& Electronic Media, 50(2), 305-322.

Mastro, D. E., \& Tropp, L. R. (2004). The effects of interracial contact, attitudes, and stereotypical portrayals on evaluations of Black television sitcom characters. Communication Research Reports, 21(2), 119-129.

Mummendey, A., \& Otten, S. (2001). Aversive discrimination. In R. Brown \& S. L. Gaertner, Handbook of social psychology: Intergroup processes (pp. 112-132). Oxford: Blackwell.

Mutz, D. C., \& Goldman, S. K. (2010). Mass media. In J. F. Dovidio, M. Hewstone, P. Glick, \& V. M. Esses (Eds.), Handbook of prejudice, stereotyping, and discrimination (pp. 241258). London: Sage.

Nacos, B. L., \& Torres-Reyna, O. (2007). Fueling our fears: Stereotyping, media coverage, and public opinion of Muslim Americans. Rowman \& Littlefield.

Nisbet, E.C., Ostman, R., \& Shanahan, J. (2009). Public opinion toward Muslim Americans: Civil liberties and the role of religiosity, ideology, and media use. In A. Sinno’s (ed.) Muslims in Western Politics. (pp. 161-199). Bloomington: Indiana University Press.

Ortiz, M., \& Harwood, J. (2007). A social cognitive theory approach to the effects of mediated intergroup contact on intergroup attitudes. Journal of Broadcasting \& Electronic Media, $51,615-631$. 
Paolini, S., Harwood, J., \& Rubin, M. (2010). Negative intergroup contact makes group memberships salient: Explaining why intergroup conflict endures. Personality and Social Psychology Bulletin, 36, 1723-1738.

Pettigrew, T. F., \& Tropp, L. R. (2006). A meta-analytic test of intergroup contact theory. Journal of Personality and Social Psychology, 90, 751-783.

$= \pm$

Power, J. G., Murphy, S. T., \& Coover, G. (1996). Priming prejudice: How stereotypes and counter-stereotypes influence attribution of responsibility and credibility among ingroups and outgroups. Human Communication Research, 23, 36-58.

Pratto, F., Sidanius, J., Stallworth, L. M., \& Malle, B. F. (1994). Social dominance orientation: A personality variable predicting social and political attitudes. Journal of Personality and Social Psychology, 67(4), 741-763.

Ramasubramanian, S. (2011). The impact of stereotypical versus counterstereotypical media exemplars on racial attitudes, causal attributions, and support for affirmative action. Communication Research, 0093650210384854.

Ramasubramanian, S. (2013). Intergroup contact, media exposure, and racial attitudes. Journal of Intercultural Communication Research 42, 54-72.

Reynolds, W. M. (1982). Development of reliable and valid short forms of the Marlowe-Crowne Social Desirability Scale. Journal of Clinical Psychology, 38, 119-125.

Riek, B. M., Mania, E. W., \& Gaertner, S. L. (2006). Intergroup threat and outgroup attitudes: A meta-analytic review. Personality and Social Psychology Review, 10(4), 336-353. 
Saleem, M., \& Anderson, C. A. (2013). Arabs as terrorists: Effects of stereotypes within violent contexts on attitudes, perceptions, and affect. Psychology of Violence, 3(1), 84-99.

Saleem, M., Prot, S., Anderson, C.A., Lemieux, A.F (2015). Exposure to Muslims in media and support for public policies harming Muslims. Communication Research. DOI: $10.1177 / 0093650215619214$.

Saleem, M., Prot, S., Cikara, M., Lam, B. C. P., Anderson, C. A., \& Jelic, M. (2015). Cutting Gordian knots: Reducing prejudice through attachment security. Personality and Social Psychology Bulletin, Advance online, doi:10.1177/0146167215601829

Schiappa, E., Gregg, P. B., \& Hewes, D. E. (2005). The parasocial contact hypothesis. Communication Monographs, 72, 92-115.

Shaheen, J. (2009). Reel bad Arabs: How Hollywood vilifies a people. Northampton, MA: Olive Branch Press.

Sides, J. \& Gross, K. (2013). Stereotypes of Muslims and support for the war on terror. Journal of Politics, 75, 583-598.

Stephan, W., \& Stephan, C. W. (2000). An integrated threat theory of prejudice. In S. Oskamp (Ed.), Reducing prejudice and discrimination (pp. 23-45). Hillsdale, NJ: Erlbaum.

Talaska, C. A., Fiske, S. T., \& Chaiken, S. (2008). Legitimating racial discrimination: Emotions, not beliefs, best predict discrimination in a meta-analysis. Social justice research, 21(3), 263-296.

This article is protected by copyright. All rights reserved. 
Tan, A. S., Fujioka, Y., \& Tan, G. (2000). Television use, stereotypes of African Americans and opinions on affirmative action: An affective model of policy reasoning. Communication Monographs, 67, 362-371.

The Brookings Institute (2011). "What it means to be American." Retrieved June 1, 2015 from http://www.brookings.edu/ /media/research/files/reports/2011/9/06-americanattitudes/0906_american_attitudes.pdf

Tukachinsky, R., Mastro, D., \& Yarchi, M. (2015). Documenting portrayals of race/ethnicity on primetime television over a 20-year span and their association with national-level racial/ethnic attitudes. Journal of Social Issues, 71(1), 17-38.

Turner, R. N., Hewstone, M., \& Voci, A. (2007). Reducing explicit and implicit prejudice via direct and extended contact: The mediating role of self-disclosure and intergroup anxiety. Journal of Personality and Social Psychology, 93, 369-38.

Zakrisson, I. (2005). Construction of a short version of the Right-Wing Authoritarianism (RWA) Scale. Personality and Individual Differences, 39(5), 863-872.

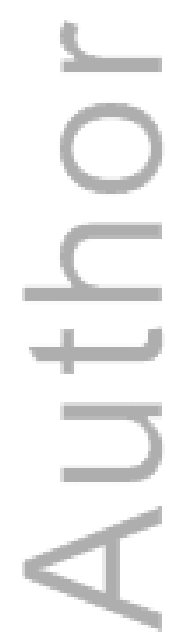


Table 1. Study 1: Descriptive Statistics and Bivariate Correlations of Hypothesized Variables $($ Ns $=178-210)$

Measure

\begin{tabular}{lrccccccc} 
Mean & SD & Alpha & 1 & 2 & 3 & 4 & 5 & 6 \\
\hline 3.58 & 1.74 & .91 & - & & & & & \\
-0.01 & .79 & .71 & .04 & - & & & & \\
1.74 & .91 & .97 & $.32^{* * *}$ & $-.14^{*}$ & - & & & \\
2.34 & .91 & .87 & $.37^{* *}$ & $-.20^{*}$ & $.65^{* * *}$ & - & & \\
2.02 & .93 & .94 & $.30^{* * *}$ & $-.24^{* *}$ & $.59^{* * *}$ & $.61^{*}$ & - &
\end{tabular}

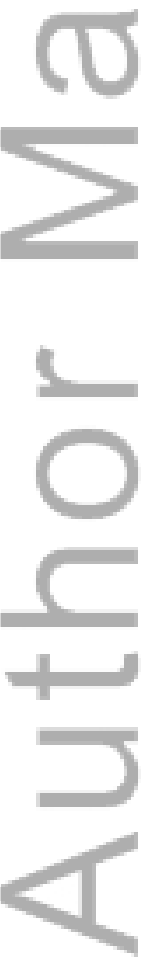




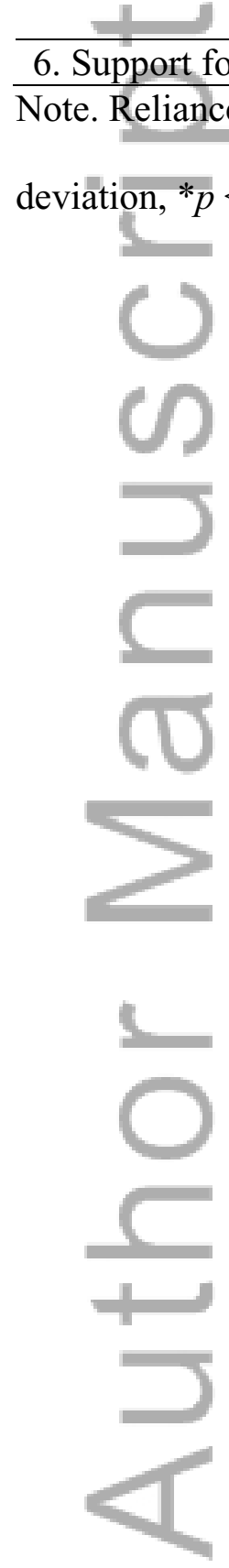

This article is protected by copyright. All rights reserved. 
Table 2. Study 2: Descriptive Statistics and Bivariate Correlations of Hypothesized Variables $(N=351)$

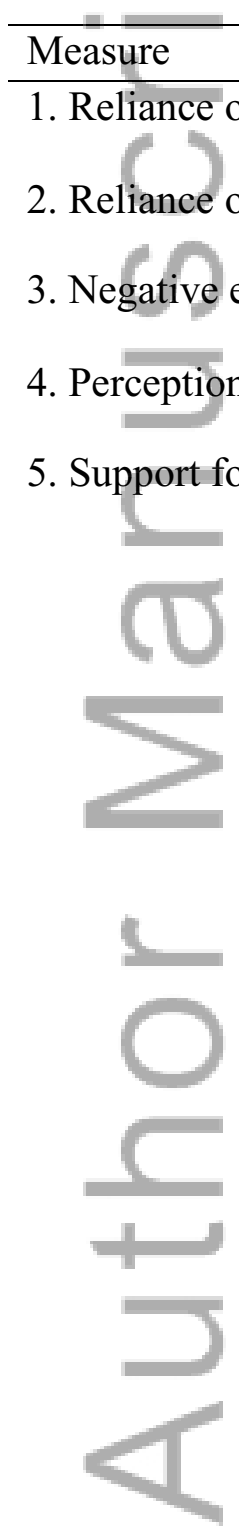


$+$

\begin{tabular}{|c|c|c|c|c|c|c|c|c|c|}
\hline 6. Support for military action in Muslim countries & 3.34 & .89 & .82 & $.22^{* *}$ & $-.11^{*}$ & $.52^{* *}$ & $.60^{* *}$ & $.46^{* *}$ & - \\
\hline
\end{tabular}

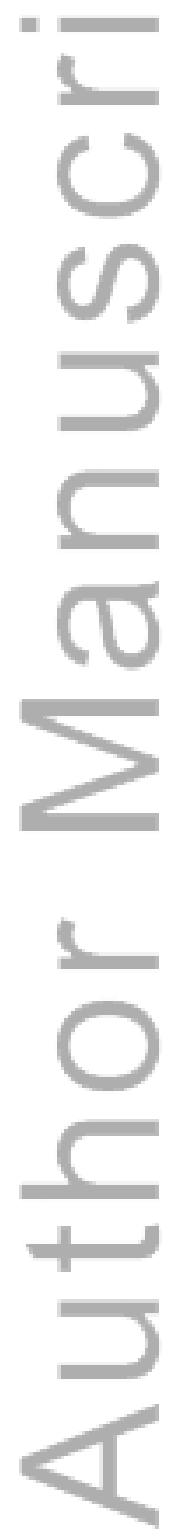


Figure 1. Study 1. The effect of reliance on direct and media-based contact for information about Muslims (Time 1) on negative emotions towards Muslims and perceptions of Muslims as aggressive (Time 2) and support for public policies harming Muslims domestically and internationally (Time 3 ). Note. Standardized coefficients are shown for the hypothesized paths. Dotted lines indicate non-significant paths. ${ }^{*} p<.05, * * p<.01, * * * p<.001$.

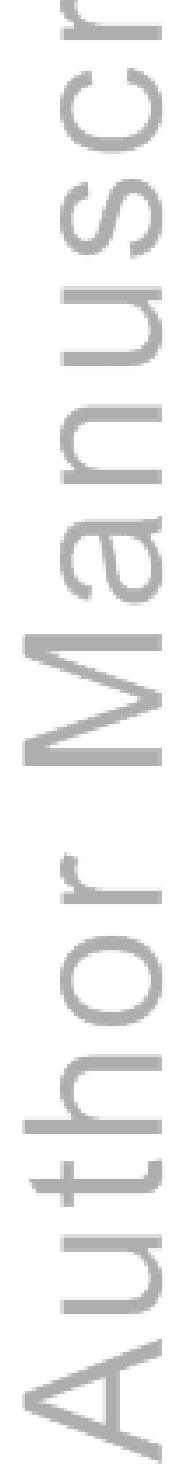




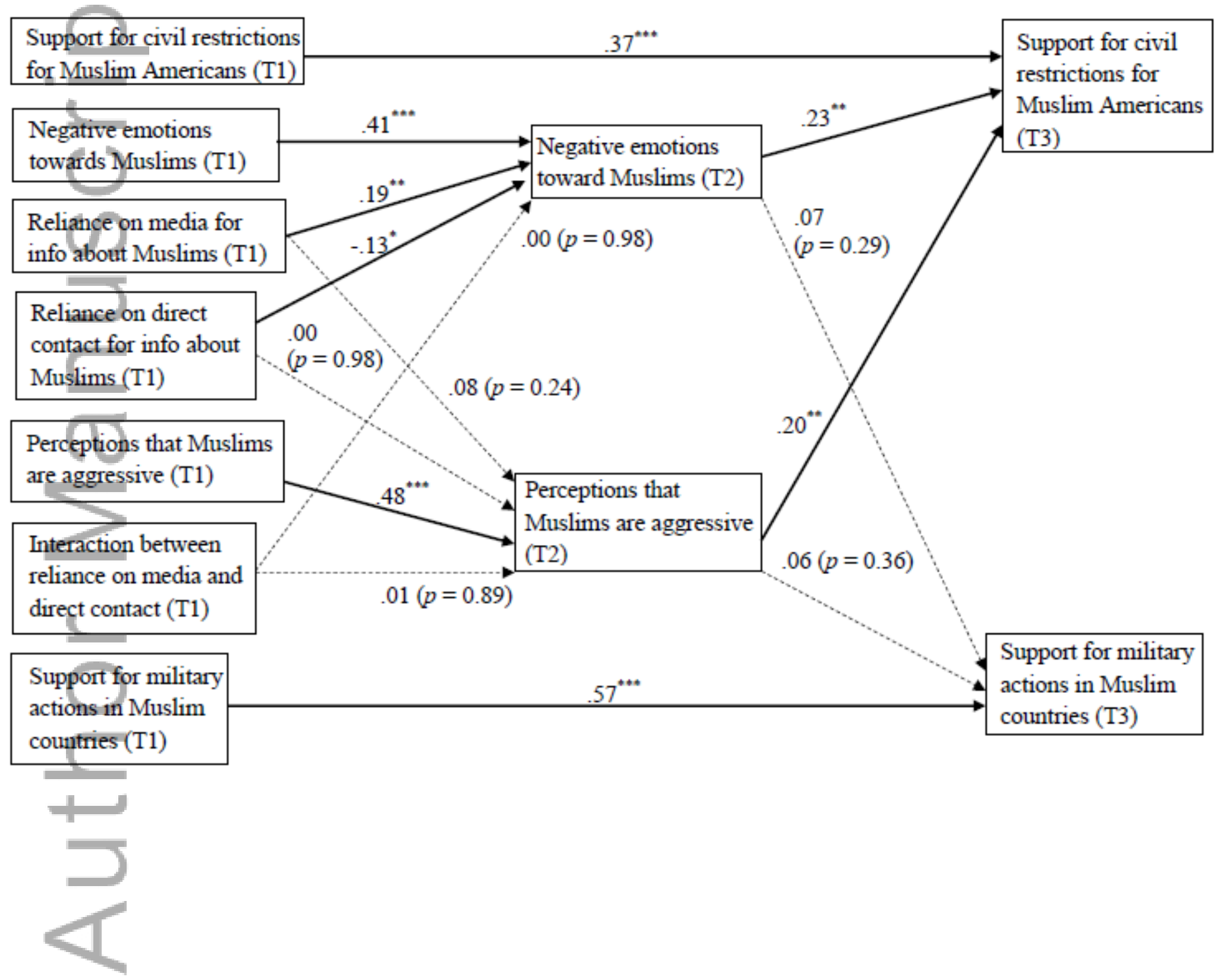

This article is protected by copyright. All rights reserved. 
Figure 2. Study 2: The effect of reliance on direct and media-based contact as sources of information about Muslims on negative emotions towards Muslims and perceptions of Muslims as aggressive and support for public policies harming Muslims domestically and internationally. Note. Standardized coefficients are shown for the hypothesized paths. Dotted lines indicate non-significant paths. ${ }^{*} p<.05, * * p<.01, * * * p<.001$

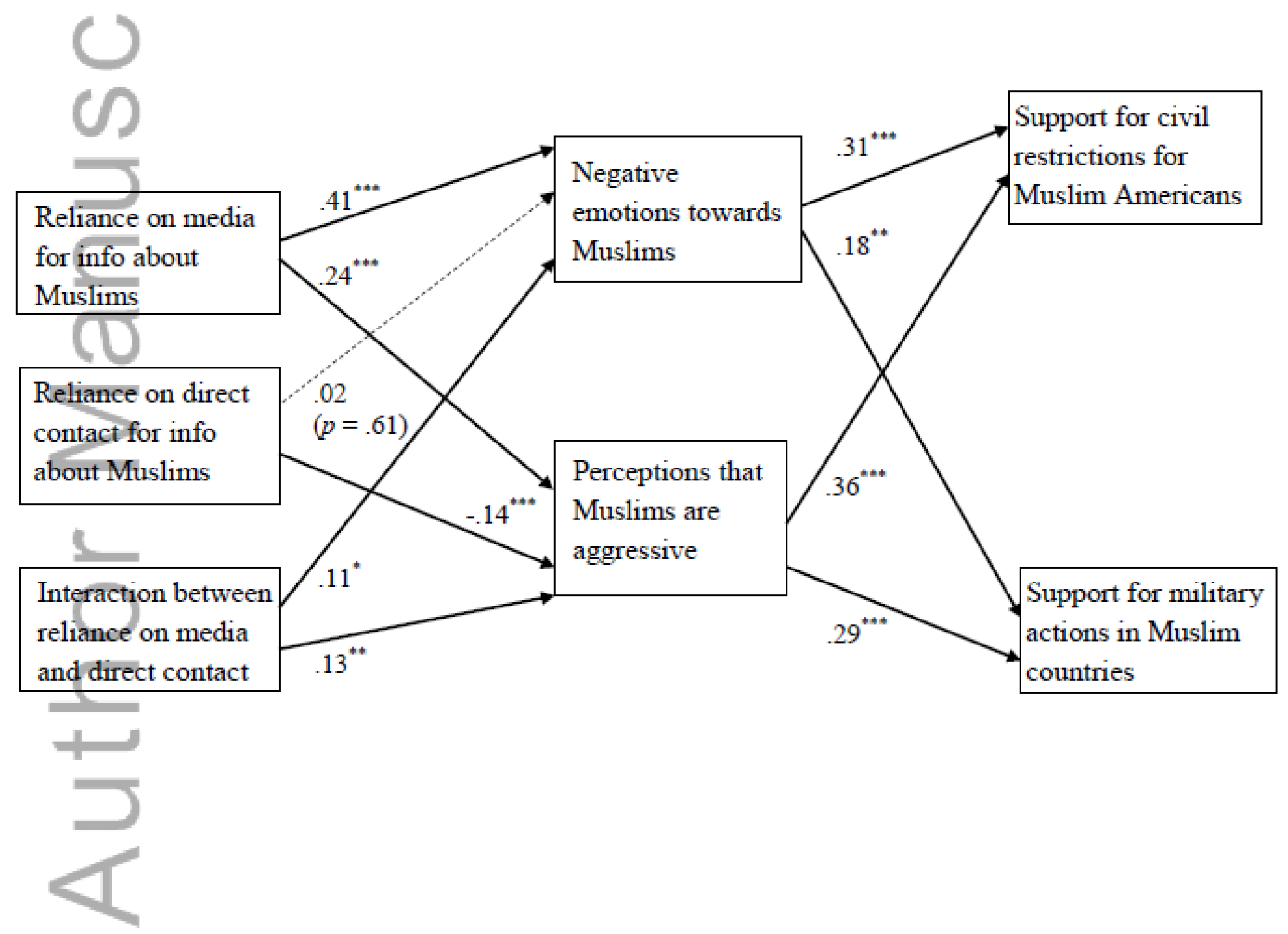

This article is protected by copyright. All rights reserved. 
Figure 3. Study 2. Perceptions of Muslims as aggressive as a function of reliance on media and reliance on contact for information about Muslims.

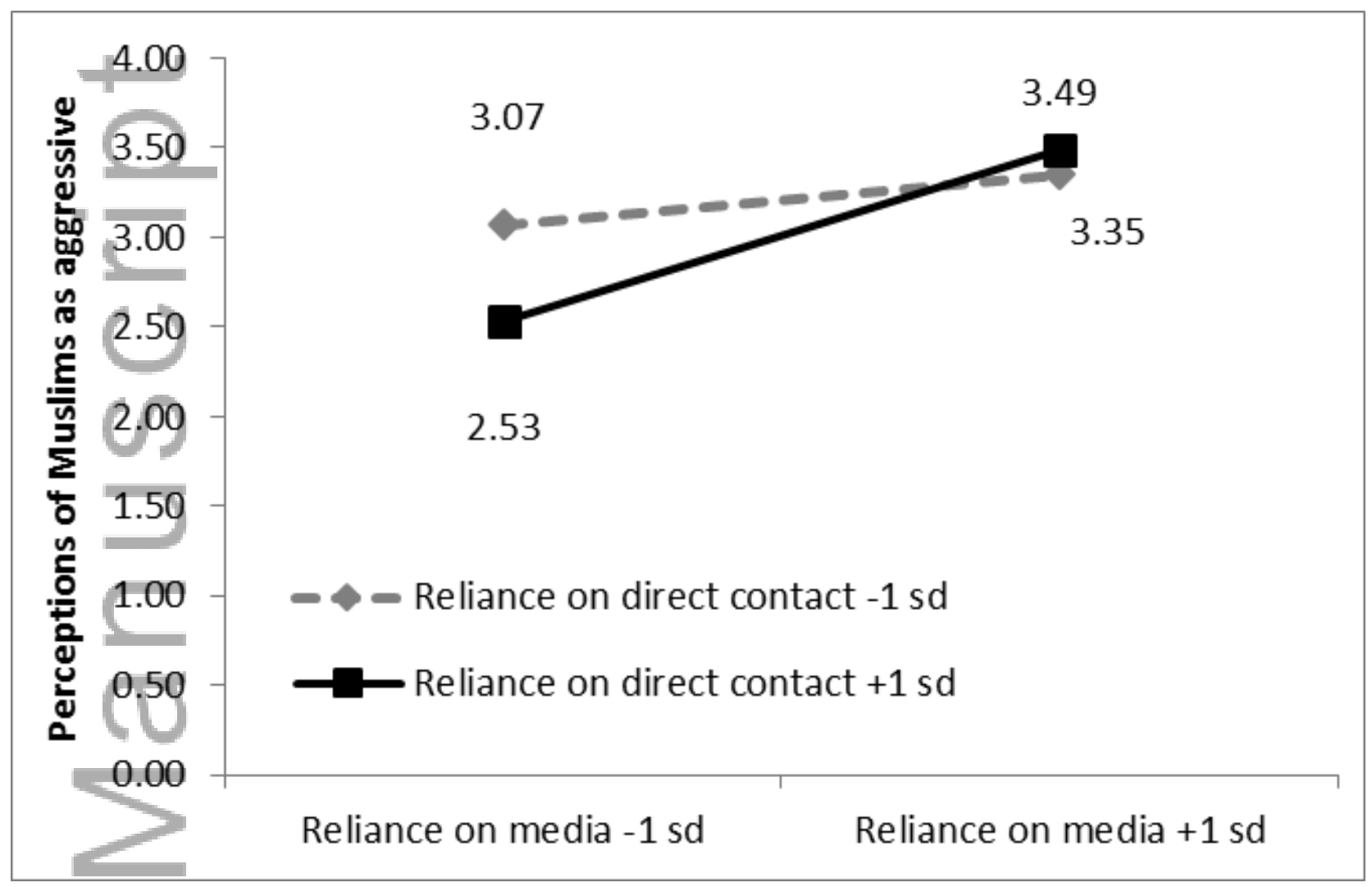

This article is protected by copyright. All rights reserved. 
Figure 4. Study 2. Negative emotions towards Muslims as a function of reliance on media and reliance on contact for information about Muslims.

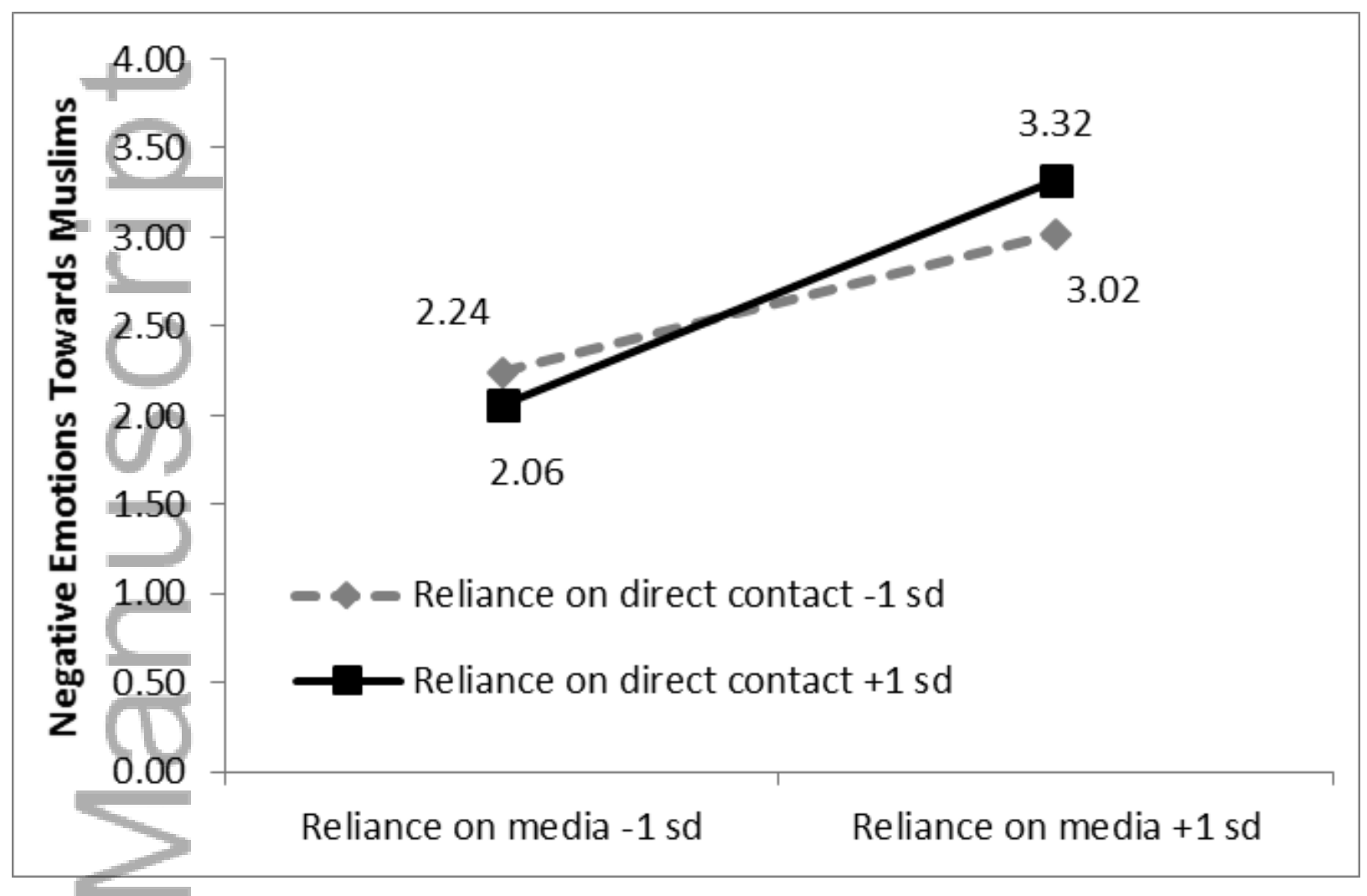

This article is protected by copyright. All rights reserved. 


\title{
Reliance on Direct and Mediated Contact and Public Policies Supporting Outgroup Harm
}

\author{
Muniba Saleem ${ }^{1}$ \\ Grace S. Yang ${ }^{2}$ \\ Srividya Ramasubramanian ${ }^{3}$
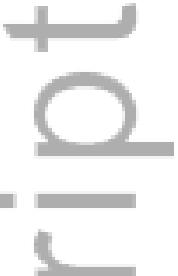 \\ Author affiliations: \\ ${ }^{1}$ Department of Communications \& Research Center for Group Dynamics, Institute for Social \\ Research, The University of Michigan, 734763 7349. saleemm@umich.edu \\ ${ }^{2}$ Department of Psychology \& Research Center for Group Dynamics, Institute for Social \\ Research, The University of Michigan, Ann Arbor, MI. \\ ${ }^{3}$ Department of Communication, Texas A\&M University, College Station, TX.
}

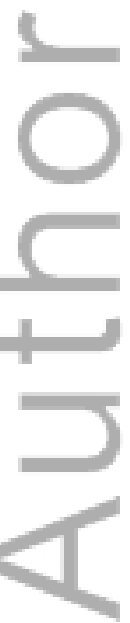

Word count: 8835 Tables: 2 Figures: 4

This article is protected by copyright. All rights reserved. 